\title{
Políticas habitacionais, segregação residencial e desigualdade no acesso às políticas públicas: uma análise a partir do acesso a serviços públicos de saúde ${ }^{1}$
}

\author{
MARCO ANDRE CADONÁ \\ Universidade de Santa Cruz do Sul - Santa Cruz do Sul - RS - Brasil \\ CLÁUDIA TIRELLI \\ Universidade de Santa Cruz do Sul - Santa Cruz do Sul - RS - Brasil \\ SÍLVIA VIRGÍNIA COUTINHO AREOSA \\ Universidade de Santa Cruz do Sul - Santa Cruz do Sul - RS - Brasil \\ DOI: $10.17058 /$ redes.v22i1.8518
}

\section{Resumo}

O artigo apresenta uma análise sobre a repercussão das políticas de habitação social e de direito à moradia, desenvolvidas pelo governo brasileiro a partir de 2009, sobre a dinâmica de reprodução social de populações pobres. Tomando como referência empírica um projeto habitacional do "Programa Minha Casa, Minha Vida", na cidade de Santa Cruz do Sul (RS), o estudo utiliza as categorias de "nova pobreza" e de "segregação residencial" como referências teóricas para avaliar como esses programas afetam as redes de sociabilidade das populações pobres, (re)definindo o seu acesso a bens e serviços públicos, em especial serviços de saúde.

Palavras Chave: Nova pobreza. Segregação residencial. Políticas públicas. Serviços de saúde.

Housing policies, residential segregation and inequality in access to public policies: an analysis based on access to public health services

\begin{abstract}
The article presents an analysis of the impact of social housing policies and the right to housing, developed by the Brazilian government from 2009, on the dynamics of social reproduction of poor. Taking as empirical reference a housing project of the "My Home, My Life Program", in the city of Santa Cruz do Sul (RS), the study uses the categories of "new poverty" and "residential segregation" as theoretical references to assess how these programs affect the social networks of the poor, (re) defining the access to public goods and services, especially health services.
\end{abstract}

Keywords: New poverty. Residential segregation. Public policy. Health services. 
Políticas habitacionais, segregação residencial e desigualdade no acesso às políticas públicas: uma análise a partir do acesso a serviços públicos de saúde1

\section{Introdução}

Este artigo apresenta uma análise sobre a implementação do Programa Habitacional Minha Casa, Minha Vida, desenvolvido pelo Governo Federal no Brasil a partir de 2009, e suas repercussões sobre as condições de acesso das populações pobres a bens e serviços públicos disponibilizados no espaço urbano (saúde, educação, assistência social, mercado de trabalho, etc.). Tomandose como referência um projeto de habitação popular construído no município gaúcho de Santa Cruz do Sul - o Residencial Viver Bem - investiga-se as implicações da localização espacial de moradia sobre as dinâmicas de reprodução social das populações pobres, através dos constrangimentos que colocam para o acesso a políticas públicas, em especial aos serviços públicos de saúde. A partir de uma perspectiva relacional, considera-se que os padrões de contiguidade social e as relações de vizinhança provocam efeitos específicos nos distintos grupos sociais, o que precisa ser investigado empiricamente. Nesse sentido, este trabalho busca não apenas construir um perfil socioeconômico das famílias que residem no projeto habitacional em estudo com base nos dados secundários produzidos pela Prefeitura Municipal de Santa Cruz do Sul, pelo Núcleo de Ação Comunitária da Universidade de Santa Cruz do Su-UNISC e pelo Censo Demográfico de 2010 (IBGE - Instituto Brasileiro de Geografia e Estatística), mas, sobretudo, produzir evidências que permitam demonstrar o que significou o deslocamento residencial dessas famílias sob o ponto de vista do acesso a serviços públicos de saúde existentes na cidade de Santa Cruz do Sul.

A análise dos dados permite problematizar a perspectiva teórica e política que estabelece uma relação positiva entre políticas públicas de habitação e inclusão social das populações pobres. O deslocamento dessas populações por meio da implementação de programas habitacionais, ao mesmo tempo em que garante o acesso à moradia, acaba repercutindo em diferentes dimensões de reprodução social das famílias contempladas, muitas vezes não produzindo uma maior inclusão social. São essas repercussões, contraditórias, que o artigo propõe para a análise, com base nos dados empíricos analisados e na bibliografia que estuda as interrelações entre segregação residencial, pobreza e desigualdade no acesso às políticas públicas.

O artigo está estruturado em duas seções, além dessa introdução e dos comentários finais. Na primeira seção, apresenta-se, com base na literatura da área de Estudos Urbanos, as inter-relações em segregação residencial e o acesso a serviços e bens públicos. $\mathrm{Na}$ segunda seção são apresentados dados referentes ao município de Santa Cruz do Sul e ao perfil sociodemográfico dos moradores do residencial investigado, ao mesmo tempo em que se analisa as repercussões do deslocamento no espaço urbano sobre o acesso a serviços de saúde, em especial os serviços de saúde oferecidos através das Estratégias de Saúde da Família (ESF).
1 O artigo é resultado de uma pesquisa, ainda em curso, sobre os efeitos da segregação residencial sobre o acesso das populações pobres, residentes em cidades médias, às políticas públicas. Esta pesquisa está sendo desenvolvida pelos autores na Universidade de Santa Cruz do Sul/RS/Brasil. 


\section{A dimensão espacial das políticas públicas e a heterogeneidade da "nova pobreza urbana"}

As investigações sobre como a dimensão espacial condiciona o acesso às políticas públicas destinadas às populações pobres, ainda que não seja recente na bibliografia que analisa desigualdades sociais, pobreza e políticas públicas no Brasil, ganharam importância nas últimas décadas. Isso ocorreu em virtude das mudanças vivenciadas no País, em especial a implementação de políticas públicas direcionadas à erradicação da pobreza, mas também "'em decorrência de perspectivas teóricas recentes que vêm apresentando novas propostas de análise da pobreza e da segregação social.

Embora haja concordância quanto às melhorias que ocorreram a partir dos anos 2000 em praticamente todos os indicadores relacionados à qualidade de vida da população brasileira, alguns estudos (MARQUES et al., 2012; ARRETCHE, 2015, MARQUES, 2009) apontam que as políticas públicas não beneficiaram a todos os grupos sociais de maneira equânime:

\footnotetext{
[...] as políticas sociais no Brasil - sejam as universais, sejam as focalizadas [...] - não levam normalmente em conta a distribuição desigual dos diversos grupos sociais no espaço urbano, assim como as dinâmicas espaciais, no que diz respeito tanto à formulação como à implementação. (TORRES, MARQUES, BICHIR, 2006, p. 231-232).
}

Constata-se, nesse sentido, que a dimensão espacial nem sempre é incorporada como uma dimensão importante de análise, de planejamento e de implementação das políticas públicas, ainda que condicione as possibilidades de acesso dos indivíduos e das famílias a serviços e bens públicos, incidindo, portanto, nas estratégias que objetivam superar/romper com situações de pobreza.

Sejam pobres ou não, as populações não se localizam "naturalmente" no espaço. A localização das populações é condicionada pelas dinâmicas de desenvolvimento econômico dos locais e das regiões, pelas políticas que envolvem o ordenamento dos espaços e pelas estratégias individuais e familiares. De acordo com Torres, Marques e Bichir,

\footnotetext{
[...] as principais causas da segregação seriam dadas pela lógica do mercado de trabalho, pela dinâmica do mercado imobiliário e pelas políticas públicas. [...] cada uma dessas dimensões atua de modo diferenciado - e coordenado - no sentido de produzir separação residencial entre diferentes grupos de renda. (TORRES, MARQUES, BICHIR, 2006, p.239).
}

No caso das políticas habitacionais destinadas às populações de baixa renda, desenvolvidas a partir do final dos anos 2000 no Brasil, as mesmas tiveram muita importância no reordenamento do espaço urbano. Porém, mesmo que os programas habitacionais tenham sido formulados dentro de uma perspectiva de ampliação do direito à cidade, eles implicaram em remoções ou deslocamentos de indivíduos e famílias, em estratégias de apropriação de novos espaços, provocando diversas transformações nos modos de vida desses grupos. Entre essas, pode-se observar alterações nas relações estabelecidas entre 
indivíduos, famílias e vizinhança, nas relações com os locais de trabalho e, também, na forma de acesso aos diferentes serviços públicos. Portanto, essas dinâmicas urbanas interferiram nas relações dos indivíduos e das famílias com a própria cidade, promovendo alterações nas suas relações com os serviços oferecidos, com os espaços de trabalho, com as instituições públicas (escolas, unidades de saúde), com suas relações de amizade e de vizinhança etc.

Assim, se é importante destacar as nítidas melhoras nos indicadores sociais, observadas a partir dos anos $2000 \mathrm{em}$ todo o território brasileiro, é importante também atentar para o fato de que dados mais desagregados indicam que as políticas sociais não beneficiaram toda a população de maneira equânime, reforçando, inclusive, déficits já vivenciados por parte de populações residentes em municípios de menor dinamicidade econômica e de reduzida capacidade estatal. ${ }^{2}$

Nessa direção, pesquisa realizada por Arretche (2015), com base nos dados fornecidos pelos Censos Demográficos entre 1970 e 2010 e contemplando as cinco grandes regiões brasileiras, indica que o Brasil apresenta uma forte associação entre a riqueza das suas jurisdições, a renda da população e a oferta de serviços essenciais. A pesquisa indica que o país apresentou, desde os anos de 1970, um incremento em termos da qualidade de vida da sua população, embora ainda existam locais que não chegaram a usufruir desses benefícios, ou seja, há uma desigualdade territorial que perdura. Os resultados da pesquisa demonstram que as populações pobres de municípios ricos foram beneficiadas pela maior oferta de serviços e bens públicos nas últimas décadas, enquanto que aquelas residentes em municípios pobres permaneceram alijadas desse processo. Isto indica que a expansão dos serviços públicos beneficiou mais aqueles municípios que apresentavam maior capacidade e dinamicidade para acessar as políticas públicas, reproduzindo, de certa forma, desigualdades de condições prévias.

Em nível intramunicipal também se pode observar vários tipos de desigualdades em relação às possibilidades de acesso aos serviços públicos e ao mercado de trabalho, por parte das populações que residem nos diferentes espaços urbanos. Também sobre esse tema, pesquisas realizadas na área dos Estudos Urbanos e Regionais vêm investigando as inter-relações entre pobreza, segregação urbana e desigualdade no acesso às políticas públicas, buscando decifrar as suas dinâmicas e contribuir para o aprimoramento das políticas públicas que incidem sobre os distintos territórios e suas populações. (MARQUES et al., 2012; ARRETCHE, 2015, MARQUES, 2009).

Embora essas pesquisas se debrucem sobre políticas públicas específicas e apontem para argumentos distintos com relação às causas desses fenômenos e suas imbricações, pode-se identificar vários pontos em comum nessas análises, tais como: a) a utilização de dados empíricos que permitem um maior nível de desagregação das informações; b) o desenvolvimento de aportes teóricos que evitam tanto as macro narrativas e as determinações estruturais como explicações gerais para os processos de segregação espacial das populações pobres, quanto
2 Segundo Stein (2015), “O conceito de capacidades estatais foi desenvolvido para explicar porque alguns Estados possuem maior eficácia e eficiência em prover bens públicos, impulsionar e direcionar o desenvolvimento socioeconômico ou alcançar objetivos determinados em políticas específicas." (STEIN, 2015, p. 90). 
as abordagens atomistas centradas em capacidades individuais; c) a percepção da pobreza como um fenômeno heterogêneo e complexo que deve ser analisado nas suas múltiplas dimensões, extrapolando a questão da insuficiência de renda; d) a compreensão da dinâmica espacial como um elemento fundamental da análise, dado que ela condiciona as possibilidades dos atores no acesso aos serviços públicos e às formas de rompimento com a situação de pobreza; e) a identificação das redes sociais e individuais estabelecidas nos distintos territórios como elementos decisivos para explicar as desigualdades de acesso às políticas públicas e à superação da pobreza; f) o pressuposto de que a formulação das políticas públicas e a sua implementação nos distintos territórios acontecem por meio da interação entre os atores estatais e os atores civis.

As pesquisas e análises que se orientam por essas perspectivas têm buscado construir referenciais teóricos e metodológicos que auxiliem na compreensão dos fenômenos observados empiricamente e forneçam instrumentos de análise que possam colaborar na avaliação e no aprimoramento das políticas públicas implementadas nos diferentes territórios. Referindo-se à complexidade que envolvem essas análises, Torres, Marques e Bichir (2006) afirmam que "[...] os resultados desses estudos sugerem que os padrões de relação - estruturados pelas redes de relações sociais existentes no âmbito da execução de políticas de infraestrutura e também no âmbito das comunidades que recebem esses serviços - influenciam substancialmente os resultados dessa política". (TORRES, MARQUES, BICHIR, 2006, p. 245).

Ao mesmo tempo, essas perspectivas teórico-metodológicas se contrapõem àquelas análises que consideram o espaço apenas como um local onde se desenvolvem as dinâmicas sociais, as quais seriam explicadas pelas características socioeconômicas dos indivíduos que ali se encontram distribuídos. Como enfatizam Torres, Marques e Bichir (2006), a dimensão espacial, que pode se apresentar como processo de segregação residencial, deve ser considerada enquanto fator explicativo, na medida em que restringe concretamente as possibilidades de ação dos indivíduos. Nesse sentido, os autores afirmam que

\footnotetext{
[...] indivíduos com condições sociais semelhantes, mas localizados em regiões distintas da cidade, têm acesso diferenciado a bens e serviços públicos e a elementos geradores de mobilidade social (como o emprego), assim como tendem a ser submetidos de forma diferente a agravos de diversas naturezas, dependendo das condições de segregação a que estão submetidos (TORRES, MARQUES, BICHIR, 2006, p. 232).
}

Ou seja, o local de moradia interfere diretamente na possibilidade de acesso às políticas públicas, fazendo com que os grupos populacionais situados na mesma faixa de rendimento tenham condições diferentes de qualidade de vida, dependendo do local onde residem.

E é a partir dessa perspectiva teórica e metodológica que a análise das redes de relações sociais que os indivíduos e grupos constroem (em seus espaços de convivência local, mas, também, nos espaços institucionais e que os vinculam com instituições sociais e, mesmo, com o poder público) ganha importância enquanto dimensão de análise de como as políticas públicas "alcançam" e são integradas 
nos diferentes espaços. Como afirma Marques (2009), a aquisição de várias características individuais, com as quais se pode romper com as situações de pobreza (escolaridade, rendimento, cultura, etc.), dependem das redes de relações nas quais os indivíduos se encontram inseridos nos diversos espaços.

Não se trata, evidentemente, de relativizar a importância da existência (ou da não existência) de rendimentos monetários, de trabalho, deeducação, como dimensões importantes para queindivíduos e famílias possam acessar, com maior facilidade, oportunidades e condições de vida melhores. Nesse sentido, as condições materiais objetivas, bem como as estratégias e comportamentos individuais, são importantes para a compreensão do fenômeno da pobreza e do alcance das próprias políticas de enfrentamento à pobreza. Trata-se, porém, de investigar (e de incorporar), nos estudos sobre segregação e pobreza, as relações sociais e a inserção dos indivíduos e grupos em redes sociais, como dimensões importantes a partir das quais as próprias condições estruturais ganham contornos diferenciados, fazendo com que as políticas públicas tenham repercussões diferenciadas. Como afirma Marques (2009), indicando suas conclusões a partir de pesquisas que investigam a relação entre situação de pobreza e redes sociais,

[...] a renda dos indivíduos está associada à sua escolaridade e à quantidade de pessoas residindo no domicílio, variáveis tradicionais da análise do tema, mas também ao tipo de padrão relacional dos indivíduos, ao tamanho das suas redes (para os indivíduos com fontes estáveis de rendimento), assim como à variabilidade da sociabilidade (para os indivíduos residentes em áreas segregadas). O tamanho dos efeitos dessas variáveis permite sustentar a destacada relevância das redes e da sociabilidade na explicação da renda dos mais pobres. Em todos os casos, são melhores as condições de indivíduos com redes médias, pouco locais e com sociabilidade construída em espaços organizacionais (igreja, trabalho e associações) [...]. (MARQUES, 2009, p. 498).

A dimensão espacial e as redes de sociabilidade ganham importância, assim, na análise da heterogeneidade da "nova pobreza urbana". Importante notar que as pesquisas que objetivam analisar e mensurar a pobreza se deparam, de modo geral, com muitas dificuldades e muitos desafios, dado o caráter extremamente relativo deste fenômeno; ou seja, sua percepção e mensuração estão sempre relacionadas às condições de vida existentes em cada país, ou mesmo em diferentes regiões de um mesmo país, num determinado período (ROCHA, 2006). No entanto, os analistas desta área têm buscado desenvolver aportes teóricos e técnicas de pesquisa que lhes permitam incorporar a complexidade do fenômeno e, desta forma, contribuir para a formulação e para a implementação de políticas públicas voltadas à redução das desigualdades relacionadas ao "bem viver" em cada sociedade.

Nesse sentido, Rocha $(2006 ; 2010)$ afirma que a pobreza não pode ser medida apenas por informações relacionadas à renda dos indivíduos, embora essa seja uma variável fundamental nas pesquisas sobre essa temática. A autora propõe que se leve em consideração dados sobre a "pobreza absoluta" (o mínimo necessário à sobrevivência individual) e a "pobreza relativa", a qual estima também a diversidade das condições de vida existentes nas sociedades num dado momento. A linha de pobreza relativa se articula às condições gerais da sociedade 
em termos de distribuição de renda e da mensuração das desigualdades de renda como indicador de bem-estar na sociedade como um todo.

Arretche (2015) aponta no mesmo sentido indicado por Rocha quando afirma que "[...] o acesso a serviços sociais é uma dimensão do bem-estar distinta e não redutível aos rendimentos. Assim, pessoas com mesmos ganhos podem ter padrões de vida muito diferentes caso tenham distintos acessos a serviços" (ARRETCHE, 2015, p.194). Segundo Arretche, diferentemente dos bens privados, o consumo de bens coletivos não depende apenas da decisão de compra por parte dos indivíduos. No caso dos serviços públicos, a possibilidade de acesso pode ser condicionada pelo local de moradia e pelas intervenções do poder público, o qual pode prover ou não esses serviços à população, a partir de decisões que passam pelos critérios de vários atores que integram as suas jurisdições (gestores com representação política, burocratas de carreira e "burocratas em nível de rua").

Em decorrência do surgimento de novas abordagens sobre a pobreza urbana e dos resultados de pesquisas com base em dados mais desagregados, vários estudos passaram a questionar o modelo radialconcêntrico que havia marcado os estudos urbanos no Brasil até os anos 1990. Naquele modelo, os grupos sociais mais ricos estariam situados no centro, ou próximo a ele, devido a sua maior infraestrutura em termos de bens e serviços públicos; depois se formariam diversos anéis demarcando espaços com qualidade de vida decrescente, significando que quanto mais distante a região estiver do centro, mais precária e pobre será. Esta representação das metrópoles brasileiras, segundo os seus formuladores, espelhava as contradições inerentes à reprodução do sistema capitalista periférico, o qual seria beneficiado pelos baixos custos de reprodução da força de trabalho na periferia urbana.

Em anos recentes foram apontadas várias críticas a essas explicações baseadas apenas nas determinações estruturais, devido ao fato delas interpretarem a segregação residencial e a pobreza como resultados diretos do processo de acumulação do capital, desconsiderando a heterogeneidade desses processos e a agência dos atores que se encontram nos distintos territórios.

Diversos autores, dentre os quais Rocha (2006, 2010), Arretche (2015), Torres, Marques, Bichir (2006), Marques et al (2012), ressaltam a necessidade de se tomar as questões da pobreza e da periferia, na sociedade brasileira contemporânea, como fenômenos complexos e heterogêneos. Marques et al. (2012) afirmam, nesse sentido, que a "pobreza" não pode ser tratada de maneira uniforme como se todos os indivíduos que se encontram nessa situação, independentemente dos locais onde residem, desfrutassem das mesmas condições de acesso a serviços e bens públicos. A dimensão espacial vai ser vista como um fator que incide distintamente sobre os diversos grupos sociais, afetando de diferentes formas as suas possibilidades de acesso as políticas públicas. Nesse sentido, os autores também advertem que se faz necessário trabalhar com a ideia de vária (s) periferia (s), no plural, e mais a partir de uma periferia urbana, ou hiperperiferia, como os estudos da década de 1970 e 1980 indicavam. Refletir sobre a heterogeneidade da periferia urbana implica, também, em questionar a sua vinculação direta com a pobreza, 
na medida em que diversos estudos vêm demonstrando (CALDEIRA, 2000; RAPOSO, 2012) como essas regiões mais afastadas do núcleo central das cidades têm se constituído nos locais preferenciais para a construção e a comercialização de grandes empreendimentos imobiliários, destinados a segmentos populacionais de alto poder aquisitivo (os chamados condomínios e loteamentos residenciais fechados). Este fenômeno, inicialmente vinculado às metrópoles, vem se difundindo rapidamente nos últimos anos entre médias e, mesmo, pequenas cidades, alimentado pela cultura do medo e pela propagação de uma visão utópica acerca da vida entre muros nesses condomínios fechados.

De qualquer forma, o fato de morar em áreas periféricas produz efeitos distintos sobre os diversos grupos populacionais e as suas redes de relações. Isto significa considerar as múltiplas dimensões da pobreza que ultrapassam as questões relativas à insuficiência de renda. Conforme Marques et al. (2012), as populações que vivem nessas periferias, identificadas na literatura internacional como a "nova pobreza", estão sujeitas a vários tipos de riscos sociais (violência, desemprego, dificuldades de inserção social), além de uma maior segregação residencial.

É a partir dessa perspectiva teórica, portanto, atenta à dimensão espacial e às redes de sociabilidade, que se pretende analisar as repercussões do deslocamento de famílias beneficiadas pelo Programa Minha Casa Minha Vida na cidade de Santa Cruz do Sul no acesso a bens e serviços públicos. Assim, se a análise destaca a importância do Programa Minha Casa Minha Vida no acesso ao direito à moradia, enfatiza também o quanto o deslocamento das populações beneficiadas por esse Programa Habitacional repercute nas suas condições de vida e de trabalho e no acesso aos serviços públicos, redefinindo as suas relações com a cidade.

\section{A implementação do Programa Minha Casa Minha Vida na cidade de Santa Cruz do Sul (RS): repercussões no acesso aos serviços de saúde}

Ao propor uma análise sobre as repercussões do Programa Minha Casa Minha Vida no acesso a serviços públicos de saúde das famílias que foram beneficiadas pelo Programa em Santa Cruz do Sul, um primeiro aspecto a ser destacado é que se trata de uma dinâmica que ocorre numa cidade média do Rio Grande do Sul. Ou seja, numa cidade que não está situada numa região metropolitana, mas apresenta "potenciais de absorção" de investimentos, possuindo "economia de aglomeração" (ganhos de produtividade atribuídos à aglomeração geográfica de sua população e/ou de suas atividades econômicas), ao mesmo tempo em que "não incorre em deseconomias de aglomeração, típicas das grandes metrópoles" (PEREIRA, LEMOS, 2003, p.127). Além disso, trata-se de uma cidade que tem importância regional, pois é referência para vários municípios localizados em seu entorno (em termos de produção industrial, do comércio, da criação de empregos e da presença de serviços públicos), e promove a articulação dessa região com circuitos nacionais e internacionais de produção. (SPOSITO, 2007). 
Esse aspecto é importante de ser ressaltado porque os estudos existentes no Brasil sobre pobreza, segregação residencial e desigualdades no acesso às políticas públicas, ainda que não estejam exclusivamente relacionados com as regiões metropolitanas, têm priorizado essas regiões. ${ }^{3}$

Ora, se durante as décadas de 1970 e e1980 o processo de urbanização das metrópoles brasileiras foi visto como uma espécie de retrato das configurações sociais existentes no País, marcadas por expressivas desigualdades sociais e espaciais, é preciso reconhecer que o padrão de urbanização brasileiro apresentou, já a partir dos anos de 1990, mudanças significativas. As metrópoles, apesar de continuarem crescendo proporcionalmente mais que o país, diminuíram o ritmo de seu crescimento anterior; já as cidades de porte médio, com população entre cem e quinhentos mil habitantes, ${ }^{4}$ cresceram a taxas maiores do que as metrópoles ( $4,8 \%$ e 1,3\%, respectivamente, no período entre 1980 e 1990) (SPOSITO, 2004). Esse crescimento populacional nas cidades de porte médio tem exigido novas investigações para se entender este fenômeno, pois reporta não apenas ao crescimento populacional, mas, também, a mudanças nas funções que essas cidades passaram a desempenhar tanto em seu entorno (regiões) quanto na própria dinâmica de desenvolvimento dos estados brasileiros. (MARICATO, 2000).

Santa Cruz do Sul é uma cidade média do Rio Grande do Sul, localizada na encosta inferior do nordeste do estado gaúcho, distante 150 quilômetros de Porto Alegre, numa região denominada Vale do Rio Pardo, a qual é constituída por 23 municípios. Com uma população estimada de 126.755 habitantes em 2016 (IBGE, 2016), o município de Santa Cruz do Sul tem como principal característica o histórico vínculo econômico, político e sociocultural com a produção do tabaco. Na "região fumicultora de Santa Cruz do Sul" encontra-se o maior complexo agroindustrial de tabaco do mundo (VOGT, 1997) e, especificamente na cidade de Santa Cruz do Sul, está localizado o maior complexo beneficiador de fumo em folha, contando com a presença de grandes indústrias fumageiras, tais como a Souza Cruz, a Philip Morris, a Alliance One e a Japan Tobacco.International.

A presença histórica do complexo agroindustrial do tabaco tornou Santa Cruz do Sul uma referência regional, não somente sob o ponto de vista da produção industrial, mas, também, em termos de estruturação de atividades de comércio e de diferentes serviços. Nesse sentido, o município abriga diversas instituições públicas responsáveis pela organização regional de serviços públicos como, por exemplo, aqueles relacionados à saúde, à educação, ao trabalho (Coordenadoria Regional de Saúde, Coordenadoria Regional de Educação, SINE - Sistema Nacional de Emprego). Além de ter uma estrutura universitária (com a presença de uma Faculdade e de uma Universidade) que atende diferentes regióes do Rio Grande do Sul, no campo da saúde Santa Cruz do Sul é também uma referência regional, com a presença de três hospitais (dois deles referências em diversas especialidades no Vale do Rio Pardo), um número elevado de profissionais da saúde, uma rede estruturada de serviços privados e públicos.

Ainda que tenha um dos maiores Produtos Internos Brutos (PIBs) do Rio Grande do Sul (em 2013, Santa Cruz do Sul ocupava o oitavo
3 Vários centros de pesquisa e redes de pesquisadores e instituições estão organizados em torno da temática das metrópoles, como é o caso do Centro de Estudos da Metrópole (CEM), ligado ao CEBRAP, e do Observatório das Metrópoles, rede que congrega 159 pesquisadores e 59 instituições de diferentes procedências para o desenvolvimento de pesquisas sobre 14 metrópoles brasileiras. Disponível em: <http://www.observatoriodasmetropoles.net/index. php?option=com_content $\&$ view =article\&id=46\&/temid=142\&lan $\mathrm{g}=\mathrm{p} t>$.

4 Embora os autores apresentem uma série de ressalvas para evitar que se utilize a denominação de cidades médias apenas levando em consideração o critério do tamanho da população, este não deixou de ser utilizado como uma referência, ou seja, ele é um critério necessário, mas não suficiente. (SPOSITO, 2004). 
lugar no ranking dos 10 maiores PIBs gaúchos) (FEE, 2015), parcelas importantes da população do município pertencem a famílias com rendas significativamente baixas. Segundo dados do Censo Demográfico de 2010, 23,7\% das famílias de Santa Cruz do Sul tinham renda média mensal de até dois salários mínimos, correspondendo a 9.614 famílias ou, então, a 28.072 pessoas (considerando que a média de pessoas por domicílio era de 2,92, segundo dados do Censo Demográfico de 2010) (IBGE, 2011). Destaque-se, ainda, que $89,5 \%$ da população do município residia em espaços urbanos (IBGE, 2011) e que seus indicadores de IDH (Índice de Desenvolvimento Humano), em 2010, eram altos: renda 0,782; longevidade - 0,852; educação - 0,693 (o IDH do município era 0,773, situando-se acima da média estadual e do país) (PNUD, 2010).

As informações indicadas permitem assinalar que Santa Cruz do Sul apresenta índices elevados de qualidade de vida e de desenvolvimento econômico. O que, evidentemente, não implica situação equânime dos diferentes grupos e classes sociais, nem as mesmas condições, entre esses, de acesso a serviços públicos disponibilizados no município. A parcela da população que tem renda média de até dois salários mínimos, indicada no parágrafo anterior, é ilustrativa. Mas, também, os dados do Relatório de Informações Sociais e Cadastro Único, do Ministério do Desenvolvimento Social e Combate à Fome (que reúne informações socioeconômicas das famílias brasileiras com baixa renda - com renda mensal de até meio salário mínimo por pessoa); segundo esses dados, em Santa Cruz do Sul um total de 9.768 famílias estavam inscritas no Cadastro Único em 2016, dentre as quais 1.925 tinham renda per capita familiar de até $\mathrm{R} \$ 85,00,2.022$ tinham renda per capita familiar entre $\mathrm{R} \$$ 85,01 e R\$170,00, 3.424 tinham renda per capita familiar entre $R \$ 170,01 \mathrm{e}$ meio salário mínimo e 2.397 tinham renda per capita acima de meio salário mínimo (MDS, 2016). No mês de setembro de 2016, o Programa Bolsa Família beneficiou no município um total de 3.328 famílias (cobertura de 95,9\% da estimativa de famílias pobres no município), com uma média nos benefícios concedidos de $\mathrm{R} \$ 143,97$ por família. (MDS, 2016).

Visando atender parcelas dessa população em situação de pobreza, a partir de 2010 foram construídos dois Conjuntos Residenciais em Santa Cruz do Sul, dentro do Programa Minha Casa Minha Vida: o Residencial Santo Antônio (cujas famílias beneficiadas receberam as chaves dos apartamentos em 2012) e o Residencial Viver Bem (cujas famílias beneficiadas receberam as chaves das casas no final de 2015). E é a partir de dados das famílias do Residencial Viver Bem que, a partir de agora, é analisada a repercussão que o deslocamento residencial, realizado por essas famílias ao serem beneficiadas pelo Programa Minha Casa Minha Vida, teve sob o ponto de vista do acesso a serviços públicos de saúde.

\section{O Conjunto Residencial “Viver Bem".}

Como foi indicado anteriormente, foi a partir de 2012 que o Programa Minha Casa Minha Vida efetivamente passou a contemplar famílias em situação de pobreza no município de Santa Cruz do Sul. Naquele ano, o poder público municipal entregou as chaves para as 
famílias beneficiadas do primeiro Conjunto Residencial vinculado àquele Programa no município: o "Residencial Santo Antônio".

No Residencial Santo Antônio foram contempladas 242 famílias (dentre as 1.112 inicialmente inscritas e pré-selecionadas para serem beneficiadas), com apartamentos de $43,24 \mathrm{~m}^{2}$ (com sala, cozinha, dois dormitórios e um banheiro). As famílias assinaram contratos prevendo o pagamento de $10 \%$ de suas rendas brutas num prazo de dez anos, com valor mínimo de $\mathrm{R} \$ 50,00$ mensais. Foram beneficiadas famílias em condições de vulnerabilidade social que residiam, anteriormente, em áreas de risco e áreas insalubres do perímetro urbano do município. Nesse sentido, as famílias contempladas não necessariamente optaram pelo deslocamento urbano, pois foram removidas pelo poder público municipal em função dos riscos que enfrentavam em seus antigos locais de moradia. (PREFEITURA MUNICIPAL DE SANTA CRUZ DO SUL, 2016).

No Residencial Viver Bem foram contempladas 908 famílias, das 1.757 inicialmente inscritas e pré-selecionadas. As famílias contempladas, que receberam casas de 40,7 $\mathrm{m}^{2}$ (com sala, cozinha, dois dormitórios e um banheiro), foram, prioritariamente, de pessoas deficientes, de idosos, de filhos e/ou dependentes menores de 18 anos, de mulheres responsáveis pela unidade familiar e de trabalhadores de reciclagem. As famílias contempladas também assinaram contratos prevendo o pagamento, em 10 anos, de parcelas mínimas de $R \$ 25,00$ e máximas de $R \$ 80,00$ mensais. (PREFEITURA MUNICIPAL DE SANTA CRUZ DO SUL, 2016).

Um dos dados que se destacam no perfil dos moradores do Residencial Viver Bem é que 90,6\% dos responsáveis pelas unidades familiares são mulheres. As responsáveis pelas unidades familiares são, na sua maioria, jovens entre 18 e 30 anos (39,32\%), vindo em seguida aquelas com idade entre 31 e 40 anos (28,41\%). Com relação à etnia, percebe-se neste residencial um percentual mais elevado de pessoas que se declararam negras/pretas (22,47\%), embora o maior percentual seja daquelas que se declararam brancas (69,27\%). A faixa de renda na qual se situa grande parte das famílias é mais elevada do que aquela da maioria dos responsáveis pelas unidades do Residencial Santo Antônio, pois $51,87 \%$ recebem entre 1 e 2 salários mínimos e 40,64\% recebem até um salário mínimo mensal (Figura 1).

Figura 2. Renda total mensal da unidade familiar - Residencial Viver Bem/Santa Cruz do Sul (RS)

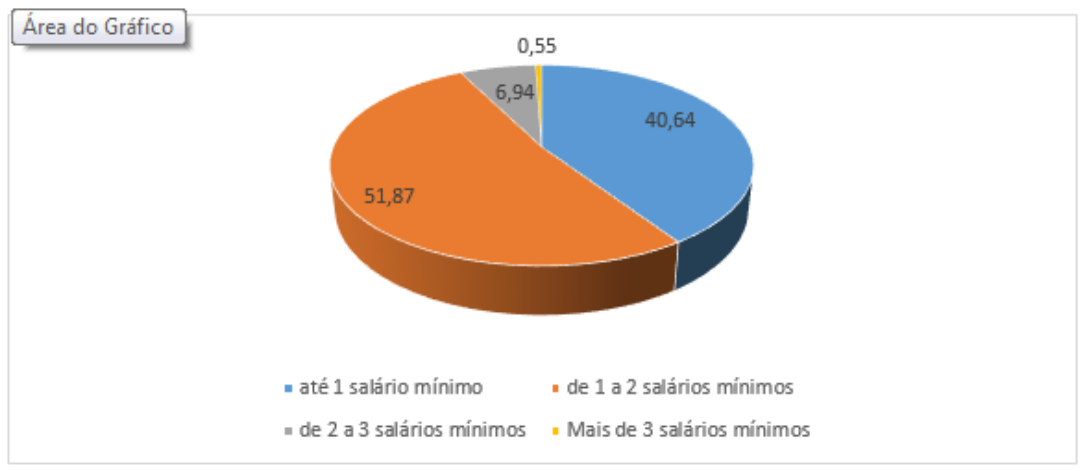

Fonte: Figura construída pelos autores a partir dos dados do Núcleo de Ação Comunitária da Universidade de Santa Cruz do Sul/UNISC. 
É importante destacar, também, o tempo transcorrido entre o cadastramento inicial e a entrada das famílias em suas novas moradias. Nesse sentido, considere-se que o início das obras do Residencial Viver Bem foi anunciado ainda em julho de 2012, com a promessa, por parte da construtora responsável, de término em 15 meses (portanto, início de 2014) (RIOVALE JORNAL, 2012). No entanto, as famílias efetivamente receberam as suas casas somente no final do ano de 2015. Evidentemente, a demora na entrega teve repercussões nos projetos/expectativas de deslocamento das famílias, o que resultou, durante o ano de 2015, em um movimento de pressão de suas lideranças junto à Prefeitura Municipal e à Caixa Econômica Federal (responsável pelo Programa Habitacional) visando garantir o término e a entrega das residências. (PORTAL GAZ, 2015).

Em relação ao local de moradia anterior ao deslocamento das famílias para o Residencial, a grande maioria residia em bairros da cidade de Santa Cruz do Sul, ainda que também foram contempladas famílias residentes em localidades do meio rural do município. O importante a ser salientado é que foram contempladas famílias que residiam em muitos bairros da cidade, sobretudo naqueles que concentram maior percentual de moradores de baixa renda. As famílias do Residencial Viver Bem vieram principalmente dos bairros Santa Vitória (101 famílias), Bom Jesus (69 famílias), Esmeralda (49 famílias), Faxinal (48 famílias), Menino Deus (45 famílias), Progresso (32 famílias), Beckemkamp (32 famílias), mas números significativos também vieram dos bairros Margarida-Aurora, Centro, Santo Antônio, Várzea, Vila Nova, Senai, Avenida, Pedreira, Arroio Grande, Carlota, Santuário, Harmonia, São João, Belvedere, Rauber, Schultz, Bom Fim, "interior" (localidades/comunidades do meio rural). (Quadro 01).

Quadro 1. Famílias residentes no Residencial Viver Bem, por local de moradia anterior ao deslocamento para o Residencial

\begin{tabular}{|c|c|c|}
\hline Avenida -13 & Faxinal - 48 & Santo Antônio - 10 \\
\hline Arroio Grande - 29 & Harmonia - 11 & Santuário - 14 \\
\hline Beckemkamp - 32 & Interior - 14 & São João - 10 \\
\hline Belvedere - 20 & Margarida-Aurora - 22 & Schultz - 19 \\
\hline Bom fim -13 & Menino Deus - 45 & Senai -29 \\
\hline Bom Jesus - 69 & Pedreira - 24 & Várzea - 17 \\
\hline Carlota - 18 & Progresso - 32 & Vila Nova - 11 \\
\hline Centro - 29 & Rauber - 20 & Outros locais - 224 \\
\hline Esmeralda - 48 & Santa Vitória - 101 & \\
\hline
\end{tabular}

Fonte: Prefeitura Municipal de Santa Cruz do Sul.

A visualização da localização dos diferentes bairros onde residiam as famílias do Residencial Viver Bem, através do Mapa apresentado a seguir, permite uma melhor compreensão do deslocamento residencial para essas famílias. Embora a maioria das famílias já residisse na região Sul da cidade de Santa Cruz do Sul (59,6\% residiam em bairros da região 
Sul), em locais próximos do Distrito Industrial (onde estão localizadas as indústrias fumageiras), muitas famílias residiam e, inclusive, no interior do município (como indicado, 14 famílias residiam em localidades do interior de Santa Cruz do Sul). Essas famílias, conforme demonstra o Cadastro que a Prefeitura Municipal fez das mesmas, tinham suas referências em termos de saúde (posto de saúde ou Estratégia Saúde da Família onde buscavam atendimento), de educação (escolas onde matriculavam as crianças e adolescentes), de trabalho (muitos, inclusive, trabalham com reciclagem e, nesse sentido, tinham seus "territórios de coleta" na cidade, compreendendo ruas, conjuntos residenciais, empresas), de comunidades religiosas, de relações de amizade e de vizinhança. (Mapa 01).

Mapa 1: Cidade de Santa Cruz do Sul, com localização dos bairros

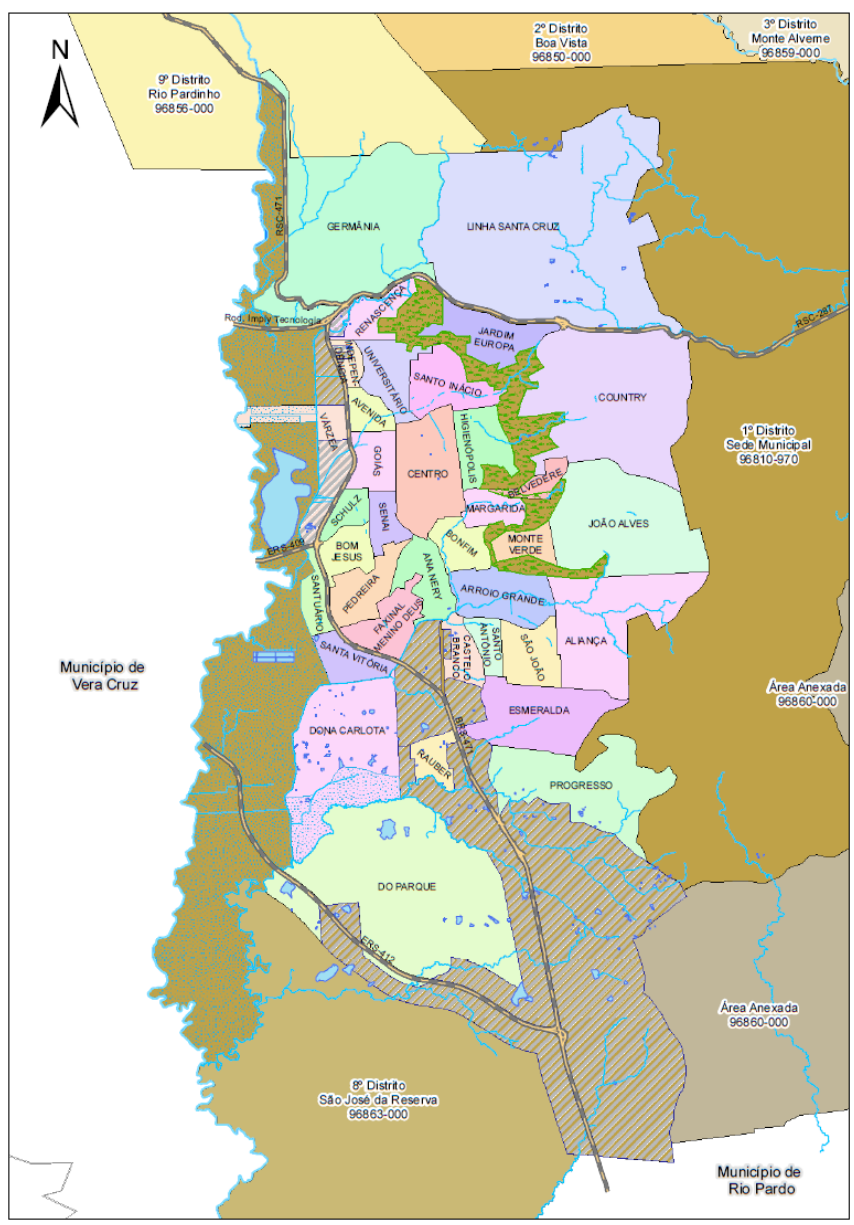

Ora, é preciso reconhecer "o papel do espaço e do lugar" nas biografias das pessoas e, nesse sentido, "reconhecer como as transações entre os indivíduos e entre as organizações são afetadas pelo espaço que os separa" (HARVEY, 1980, p. 13). Se considerado o cotidiano dessas famílias que passaram a residir num local distante do Centro da cidade e, muitas vezes, dos locais que eram, até então, as referências espaciais de organização de seus trabalhos e de suas vidas, não é difícil compreender o quanto o novo local de moradia repercutiu em termos de circulação no espaço urbano, de custos de deslocamentos, de conexões com espaços de trabalho, de serviços, de consumo e de lazer. 


\section{Repercussões do deslocamento espacial no acesso às políticas públicas: uma análise a partir dos serviços de saúde.}

Santa Cruz do Sul possui um número significativo de profissionais, de serviços e de instituições de saúde, constituindo-se numa referência principal para a maioria dos municípios do Vale do Rio Pardo no campo da saúde. De acordo com os dados do Cadastro Nacional de Estabelecimentos de Saúde (CNES), em 2014 o município possuía nove postos de saúde, trinta centros de saúde/unidades básicas, três hospitais gerais, trezentos e setenta e dois consultórios isolados, um centro de especialidades, noventa e três unidades de apoio diagnose e terapia, três unidades móveis terrestres, quatro unidades móveis de nível pré-hospitalar na área de urgência, uma farmácia municipal, uma unidade de vigilância em saúde, uma secretaria de saúde, um centro de atenção de hemoterapia, três centros de atenção psicossocial e dois pronto atendimentos (CNES, 2014).

Legalmente, o Sistema Único de Saúde (SUS) garante o atendimento universal, igualitário e integral em saúde a toda a população brasileira. $O$ acesso aos serviços públicos de saúde, no entanto, é também condicionado pela distribuição da rede de serviços nos diferentes territórios, criando desigualdades vinculadas aos locais de moradia das pessoas e das famílias. No município de Santa Cruz do Sul, essa situação ganha ainda maior importância se considerado que, sob o ponto de vista da atenção básica de saúde, o município tem somente 14 equipes que compõem a Estratégia Saúde da Família (ESF), cobrindo apenas 47,3\% de seu território (FISCHBORN, 2016).

Cabe destacar que a Estratégia Saúde da Família ocupa um espaço de fundamental importância na implementação das políticas de saúde vinculadas ao SUS (Sistema Único de Saúde). Constitui uma "porta de entrada" do Sistema e compreende um conjunto de ações de saúde, no âmbito individual e coletivo, abrangendo a promoção da saúde, a prevenção de agravos, o diagnóstico, o tratamento, a reabilitação, a redução dos danos e a manutenção da saúde; numa perspectiva de desenvolvimento da atenção integral em saúde capaz de impactar não somente na saúde, mas, também, na autonomia das pessoas e nos determinantes de saúde das populações (BRASIL, Ministério da Saúde, 2012). Cada ESF está formada por uma equipe de profissionais, de modo geral um (a) médico (a), enfermeiros (as), técnicos (as) de enfermagem, agentes comunitários (as) de saúde, devendo essa equipe atender uma população de, aproximadamente, 4.000 pessoas (BRASIL. Ministério da Saúde, 2012). Em especial os agentes comunitários de saúde, além de acompanharem as famílias localizadas nos territórios das ESFs (diagnóstico de saúde, informações, encaminhamentos etc.), muitas vezes colocamse como "interlocutores" das populações não somente no sistema de saúde, mas, também, junto às instituições públicas e aos poderes públicos municipais. (FISCHBORN, 2016). Constituem esses profissionais de saúde, nesse sentido, elos a partir dos quais indivíduos, famílias e comunidades encaminham demandas por atendimento especializado na área da saúde, mas, também, as demandas locais, comunitárias, junto a diferentes espaços de atuação do poder público, em especial o municipal (câmara de vereadores, secretarias municipais, autoridades municipais). 
Em que pese a reduzida cobertura da ESF no município de Santa Cruz do Sul, uma parcela significativa dentre as famílias do Residencial Viver Bem tinha vinculação com uma ESF ou, então, com uma Unidade Básica/ Posto de Saúde/ "Hospitalzinho" nos locais que residiam no período anterior ao deslocamento. Para ser preciso, $67,2 \%$ das famílias tinham alguma referência de local de saúde antes da mudança para o novo local de moradia (Quadro 02). Tinham, portanto, locais nos quais encontravam as primeiras referências quando precisavam de algum serviço de saúde, mas, também, profissionais através dos quais estabeleciam relações com outros espaços de atendimento à saúde (hospital, atendimentos especializados) e com espaços institucionais e políticos do município.

Observe-se, a partir dos dados do Quadro 02, que muitas famílias indicaram como referência as ESFs, justamente o espaço das políticas de saúde vinculado ao SUS em que há o comprometimento dos profissionais de saúde em estabelecer uma relação de maior proximidade com as famílias localizadas em seus territórios de atuação. Nesse sentido, e como afirmado anteriormente, são justamente com esses profissionais que as populações têm condições de construir uma relação que possibilite alcançar espaços institucionais e políticos que, de uma forma individualizada, teriam maior dificuldade de acessar.

Quadro 2. Sistema de Saúde da Atenção Básica frequentado pelas famílias do Residencial Viver Bem.

\begin{tabular}{|c|c|c|}
\hline $\begin{array}{c}\text { Unidade de Saúde indicada como } \\
\text { Referência }\end{array}$ & $\begin{array}{l}\text { Número de } \\
\text { Famílias }\end{array}$ & $\begin{array}{l}\text { \% sobre o total } \\
\text { (908 famílias) }\end{array}$ \\
\hline Posto Arroio Grande & 38 & 4,2 \\
\hline Posto Avenida & 44 & 4,8 \\
\hline Posto Belvedere & 21 & 2,3 \\
\hline UBS Boa Vista & 02 & 0,2 \\
\hline ESF Bom Jesus & 27 & 2,9 \\
\hline ESF Cristal Harmonia & 62 & 6,8 \\
\hline UBS Esmeralda & 103 & 11,3 \\
\hline UBS Farroupilha & 32 & 3,5 \\
\hline ESF Faxinal & 38 & 4,2 \\
\hline ESF Gaspar Bartholomay & 19 & 2,1 \\
\hline ESF Glória Imigrante & 18 & 2,0 \\
\hline UBS Jacob Smidt & 28 & 3,1 \\
\hline UBS Linha Santa Cruz & 05 & 0,5 \\
\hline ESF Margarida Aurora & 18 & 2,0 \\
\hline ESF Menino Deus & 49 & 5,4 \\
\hline ESF Pedreira & 32 & 3,5 \\
\hline UBS Pinheiral & 01 & 0,1 \\
\hline ESF Carlota Rauber & 34 & 3,7 \\
\hline ESF Rio Pardinho & 08 & 0,9 \\
\hline ESF SENAI & 22 & 2,4 \\
\hline UBS Verena & 09 & 1,0 \\
\hline TOTAL & 610 & 67,2 \\
\hline
\end{tabular}

Fonte: Núcleo de Ação Comunitária da Universidade de Santa Cruz do Sul/UNISC 
Evidentemente, o deslocamento das famílias para seus novos locais de moradia redefiniu a relação que tinham com os espaços e as instituições de saúde que utilizavam até então, sobretudo pela distância que o novo local de moradia apresenta em relação aos seus locais de origem. Nesse sentido, as famílias que residiam em bairros localizados numa direção oposta da cidade ou em comunidades do meio rural do município, como é o caso da comunidade de Rio Pardinho, foram as mais prejudicadas em relação ao acesso aos serviços de saúde, pois, se quisessem manter suas relações com esses espaços anteriores, teriam que percorrer distâncias maiores e arcar com os custos desse deslocamento.

Mesmo que houvesse disposição e condições das famílias em se deslocarem para seus locais anteriores de referência, as dificuldades se colocariam pela própria organização dos serviços básicos de saúde, especificamente no caso das ESFs. Como indicado anteriormente, cada ESF tem uma atuação dentro de um território onde residem 4.000 pessoas, um número que se torna elevado quando as equipes de saúde não possuem profissionais em quantidade necessária (FISCHBORN, 2016).

O deslocamento das famílias do Residencial Viver Bem teve uma repercussão ainda maior na relação com as instituições de saúde. Como esse Residencial foi construído numa área periférica da cidade, na qual até então não havia moradores, a infraestrutura (inclusive em termos de serviços públicos de água, saneamento, energia) precisou ser construída. No caso dos serviços de saúde, mas, também, de educação, o poder público municipal não construiu uma estrutura própria para o Residencial. Nesse sentido, apostou na própria possibilidade dos moradores construírem soluções ou, como ocorreu no caso da saúde, incentivou as famílias à manterem seus vínculos com os bairros em que residiam anteriormente. Considerando a distância em relação aos bairros em que residiam, suas condições de renda (segundo dados cadastrais, 381 famílias estão inseridas no Programa Bolsa Família), a relação com o mercado de trabalho, além da própria organização dos serviços de saúde que circunscreve a sua atuação a territórios próximos, evidentemente a relação das famílias do Residencial com os serviços de saúde se fragilizou a partir do deslocamento.

\section{Comentários Finais}

As indicações construídas a partir da relação das famílias do Conjunto Residencial Viver bem com os serviços de saúde, evidentemente, não relativizam a importância e o significado histórico de Programas Habitacionais como é o caso do Minha Casa Minha Vida. $O$ direito à moradia é um ausente histórico para parcelas significativas da população brasileira e, nesse sentido, políticas habitacionais comprometidas com a garantia desse direito, especialmente para as populações pobres, são importantes estratégias de inclusão social e de enfrentamento das desigualdades sociais e da pobreza.

No entanto, é preciso notar que certos grupos populacionais, 
localizados em espaços mais segregados do espaço urbano, ainda têm maiores dificuldades de usufruir dos serviços públicos disponibilizados nas cidades, o que pode limitar as suas possibilidades de rompimento com a situação de pobreza em que se encontram. O quanto as redes de sociabilidade interferem nas possibilidades de rompimento com a pobreza e qual é a capacidade desses grupos de redefinirem suas relações ainda é algo que necessita de maiores investigações. O que o estudo realizado permite afirmar é que os deslocamentos para lugares periféricos da malha urbana podem resultar em consequências negativas sobre a qualidade de vida das populações pobres, fator que precisa ser considerado pelos agentes públicos envolvidos na implementação das políticas habitacionais em nível municipal.

\section{Referências}

AMORIM FILHO, Oswaldo; SERRA, Rodrigo Valente. Evolução e perspectivas do papel das cidades médias no planejamento urbano e regional. Brasília: IPEA, 2001.

ARRETCHE, Maria Teresa da Silva (org.). Trajetórias das desigualdades: como o Brasil mudou nos últimos cinquenta anos. São Paulo: UNESP, 2015 .

BRASIL. Ministério da Saúde. Portal da Saúde. Disponível em: <http:// dab.saude.gov.br/portaldab/ape_esf.php>. Acesso em: 29 set. 2016.

- Ministério do Desenvolvimento Social. Relatório de Informações Sociais. Disponível em: http://aplicacoes.mds.gov.br/ sagi/RIv3/geral/relatorio.php\#Vis\%C3\%A30\%20Geral. Acesso em: 22 out. 2016.

CNES (Cadastro Nacional de Estabelecimentos de Saúde). Estabelecimentos de Saúde no Município: Santa Cruz do Sul. Brasília: Ministério da Saúde, 2014.

IBGE (Instituto Brasileiro de Geografia e Estatística). Censo demográfico 2010. Brasília: IBGE, 2010. Disponível em: <http://www.sidra.ibge.gov. $\mathrm{br} / \mathrm{cd} / \mathrm{cd} 2010 \mathrm{ETRD} . \mathrm{asp}>$. Acesso em: 10 jun. 2014.

. IBGE Cidades: Santa Cruz do Sul. Disponível em: <http://www. cidades.ibge.gov.br/v3/cidades/municipio/4316808>. Acesso em: 23 out. 2016.

COSTA, Carlos Gabriel. Imigração alemã e fumicultura: A Colônia de Santa Cruz (RS) no Período Imperial Brasileiro. Spartacus, Santa Cruz do Sul, v. 1, n. 1. Disponível em: <http://www.unisc.br/site/spartacus/ edicoes/012007/costa_carlos_gabriel.pdf >. Acesso em: 27 jun. 2016.

FEE (Fundação de Economia e Estatística). Em 2013, os municípios que 
mais cresceram foram impulsionados pela recuperação da seca e pelos bons preços da agropecuária. Disponível em: <http://www.fee.rs.gov. br/indicadores/pib-rs/municipal/destaques/>. Acesso em: 22 de outubro de 2016.

FISCHBORN, Aline. Trabalho e autonomia dos trabalhadores em saúde: uma análise a partir da estratégia de saúde da família na Região 28 de Saúde (RS). Tese de Doutorado (Programa de Pós-Graduação em Desenvolvimento Regional) - Universidade de Santa Cruz do Sul, Santa Cruz do Sul: UNISC, 2016.

FUTUROS moradores do Viver Bem pressionam Caixa e Prefeitura para entrega de casas. Portal GAZ, 23 nov. 2015. Disponível em: <http://gaz. com.br/conteudos/regional/2015/11/23/61912-futuros_moradores_do_ viver_bem_pressionam_caixa_e_prefeitura_para_entrega_de_casas. html.php>. Acesso em: 22 out. 2016.

HARVEY, David. A justiça social e a cidade. São Paulo: Hucitec, 1980.

IBGE (Instituto Brasileiro de Geografia e Estatística). Censo Demográfico 2010. Rio de Janeiro: IBGE, 2011.

IPEA (Instituto de Pesquisa Econômica Aplicada). Duas décadas de desigualdade e pobreza no Brasil medidas pela PNAD/IBGE. Brasília: IPEA, 2013.

Pobreza e riqueza no Brasil metropolitano. Brasília: IPEA (Comunicação da Presidência), n. 7, ago. 2008.

KILSZTAJN, Samuel; SILVA, Dorivaldo Francisco. Distribuição regional dos serviços de saúde no Brasil. In: KILSZTAJN, Samuel; DOWBOR, Ladislau (orgs.). Economia social no Brasil. São Paulo: SENAC, p. 215240, 2001.

MAIS de R\$ 59 milhões em moradias através do PAC. Riovale Jornal, 7 jul. 2012. Disponível em: <http://www.riovalejornal.com.br/ materias/2253mais_de_r_59_milhoes_em_moradias_atraves_do_ pac>. Acesso em: 22 out. 2016.

MARICATO, Ermínia. Urbanismo na periferia do mundo globalizado: metrópoles brasileiras. Perspectiva, São Paulo, 2000, v. 14, n. 4, p. 21-33. Disponível em: <http://dx.doi.org/10.1590/S0102883920000004000045>. Acesso em: 29 jun. 2016.

MARQUES, Eduardo C. Redes sociais e instituições na construção do Estado e da sua permeabilidade. Revista Brasileira de Ciências Sociais, São Paulo, v. 14, n. 41, p. 45-67, out. de 1999.

MARQUES, Eduardo C. As Redes Sociais Importam para a Pobreza Urbana? DADOS - Revista de Ciências Sociais, Rio de Janeiro, v. 52, n. 
2, p. 471-505, 2009.

MARQUES, Eduardo et al. Os desafios da Metrópole: desigualdades sociais, estado e segregação na Metrópole. In: LAVALLE, A. O horizonte da política: questões emergentes e agendas de pesquisa. São Paulo: UNESP; CEBRAP, p. 63-96, 2012.

PNUD (Programa das Nações Unidas para o Desenvolvimento). Banco de dados agregados do PNUD, 2010. Disponível em: <http://www. atlasbrasil.org.br/2013>. Consulta em: 13 jun. 2016.

PREFEITURA Municipal de Santa Cruz do Sul. Plano de Intervenção de Trabalho Técnico Social. Santa Cruz do Sul: Prefeitura Municipal de Santa Cruz do Sul, 2013.

Processo de entrega das moradias do Viver Bem entra na reta final. Disponível em: <http://www.santacruz.rs.gov.br/noticias/999/ processo-de-entrega-das-moradias-do-viver-bem-entra-na-reta-final>. Acesso em 17 ago. 2016.

ROCHA, Sonia. Pobreza no Brasil: afinal de que se trata? Rio de Janeiro: FGV, 2006.

. Crescimento, renda e pobreza. Como ficam os pobres? XXII Fórum Nacional 2009 - Na Crise, Brasil, Desenvolvimento de uma Sociedade Ativa e Moderna. Estudos e Pesquisas, n 349, maio de 2010.

SILVA, Mozart Linhares da. Educação e etnicidade na região de Santa Cruz do Sul - RS. Revista Eletrônica de Educação. São Carlos, v. 6, no. 2, p. 340-354, nov. 2012. Disponível em: 〈http://www.reveduc.ufscar.br>

SPOSITO, Maria Encarnação Beltrão. Cidades médias: reestruturação das cidades e reestruturação urbana. In: SPOSITO, Maria Encarnação Beltrão (org.). Cidades Médias: espaços em transição. São Paulo: Expressão Popular, 2007.

. O chão em pedaços: urbanização, economia e cidades no Estado de São Paulo. Tese (Livre Docência) - Faculdade de Ciências e Tecnologia, Universidade Estadual Paulista. Presidente Prudente: UNESP, 2004.

et al. $\mathrm{O}$ estudo das cidades médias brasileiras: uma proposta metodológica. In: SPOSITO, Maria Encarnação Beltrão (org.). Cidades médias: espaços em transição. São Paulo: Expressão Popular, p. 35-67, 2007.

. Loteamentos fechados em cidades médias paulistas - Brasil. In: SPOSITO, Eliseu Savério; SPOSITO, Maria Encarnação; SOBARZO, Oscar (orgs.). Cidades médias: produção do espaço urbano e regional. São Paulo: Expressão Popular, p. 175-197, 2006. 
STEINS, Guilherme. Capacidades Estatais e Políticas Públicas: Análise das Políticas Industriais Brasileiras no Século XXI. Anais... I Seminário Internacional de Ciência Política Universidade Federal do Rio Grande do Sul, Porto Alegre, Set. 2015. Disponível em: <http://www.ufrgs. br/sicp/files/2015/09/Stein_Capacidades-Estatais-e-Pol\%C3\%ADticasP\%C3\%BAblicas_SICP_2015-1.pdf>.

TORRES, Haroldo da Gama; MARQUES, Eduardo César; BICHIR, Renato Mirandola. Políticas públicas, pobreza urbana e segregação residencial. In: CUNHA, José Marcos Pinto da. Novas metrópoles paulistas: população, vulnerabilidade e segregação. Campinas: Nepo/Unicamp, p. 231-254, 2006

VOGT, Olgário P. A produção de fumo em Santa Cruz do Sul - RS (1849 - 1993). Santa Cruz do Sul: EDUNISC, 2007.

Marco André Cadoná. Doutor em Sociologia Política - UFSC. Docente permanente do Programa de PósGraduação em Desenvolvimento Regional - Mestrado e Doutorado da Universidade de Santa Cruz do Sul-UNISC. mcadona@unisc.br

Cláudia Tirelli. Doutora em Sociologia - UFRGS. Docente permanente do Programa de Pós-Graduação em Desenvolvimento Regional - Mestrado e Doutorado da Universidade de Santa Cruz do Sul-UNISC.ctirelli@unisc.br

Sílvia Coutinho Areosa. Doutora em Serviço Social - PUCRS. Docente permanente do Programa de PósGraduação em Desenvolvimento Regional - Mestrado e Doutorado da Universidade de Santa Cruz do Sul-UNISC. sareosa@unisc.br 